\title{
Energy Efficiency of Low Quality Built Heritage: Methodological Reflections on Achieving the NZEB through a Case Study in the City of L'Aquila
}

\author{
Elisa leie*
}

\author{
Università degli Studi "G. d'Annunzio" di Chieti-Pescara, Viale Pindaro, 42 - Pescara, Italy
}

\begin{abstract}
About the building heritage and, in particular, about the widespread heritage without historical or architectural quality, it currently opens a challenge in perpetual evolution. This is the integration of innovative technological solutions for building regeneration, which can help a qualitative improvement of the living spaces and the reduction of energy consumptions. Context factors, the intensity of precipitation, the different types of soil, and the amount of solar irradiation or wind speed are doubtless the main causes of the degradation of the existing buildings.

On another way, through the control of climatic and biophysical parameters, the focus on the properties of materials and a careful design process, these variables can increase the use of renewable energy sources, becoming environmental resources to reduce energy consumption, to provide comfortable living spaces and aiming the realization of a Near Zero Energy Building.

The paper proposes a reflection on the main methodological issues emerged in the hypothesis of intervention experimented on a case study in the city of L'Aquila. The building, located near the historical center of the city, is in direct relation with important pre-existences such as the Forte Spagnolo and the San Salvatore hospital. It is an example of possible regeneration of low quality building in which the additional use of new functional spaces can increase not only energy performances, but also an increase of architectural value of the building.
\end{abstract}

Keywords: Low quality built heritage, bioclimatic parameters, building regeneration, energy efficiency, building envelope.

\section{INTRODUCTION}

Most of the civil engineering in Italy dates back to the postwar period and has been characterized by a poor interest in sustainability, until to 1991 , when the first law on energy efficiency was enacted, unlike the previously used techniques that mitigated atmospheric agents, through the massive masonry, in what we can define nowadays a perfect exploitation of passive systems. Therefore, the obsolescence of existing building heritage depends in the least on the age of the artifacts. Moreover, it is mainly due to the lack of interest in the search for the quality of the materials used and to the use of inefficient technology solutions. Therefore, a typology of low-level architecture is shown which mechanically and uncritically repeats the constructive concepts of the moment and applies them indiscriminately to every territory without taking care of integration and compatibility with the surrounding environment [1].

Property renovation must also includes ideas on the energy efficiency requirements of buildings, the main argument of the international scientific debate, that provides a complete package to support safety and security elements to their occupants [2].

*Address correspondence to this author at the University of Chieti-Pescara, "G. d'Annunzio", Viale Pindaro, 42 - 65127 Pescara, Italy; Tel: +39.085.45.37.332; E-mail: elisaieie85@gmail.com
The relevance of the connection between project, technology, and energy is nowadays real. In all its complexity and the need to face it can no longer be postponed [3]. Despite the directive of the Community legislation dating back to 2010 (2010/31 / EU "Energy performance of the buildings ") the European legislator, in that occasion, introduces the concept of nearly zero energy building, requiring national legislation to develop different plans according to the type of building that takes into account different climatic and local conditions from one zone to another. Moreover, they impose that by the end of 2020 all new buildings must reach a high-energy efficiency threshold. Their focus is to exploit renewable sources and generate energy on site so that they can cover the overall primary energy needed. The operational dimension therefore, for the specific Italian case, is in a close relationship with requalification of existing architectural heritage [4]. This gives way to a vast panorama of research and experimentation that focus and identifies the issues. In this area of radical change, the case study of the city of L'Aquila emerges (Figure 1) showing a local scenario in which planning and design have deeply dropped in the specific cultural, social, environmental, microclimatic and biophysical, in a more sensitive perspective approach, defined by today's scientific literature "caseto-case approach" [5].

Through the study of the single building, the problems, models, approach methods and generalized 


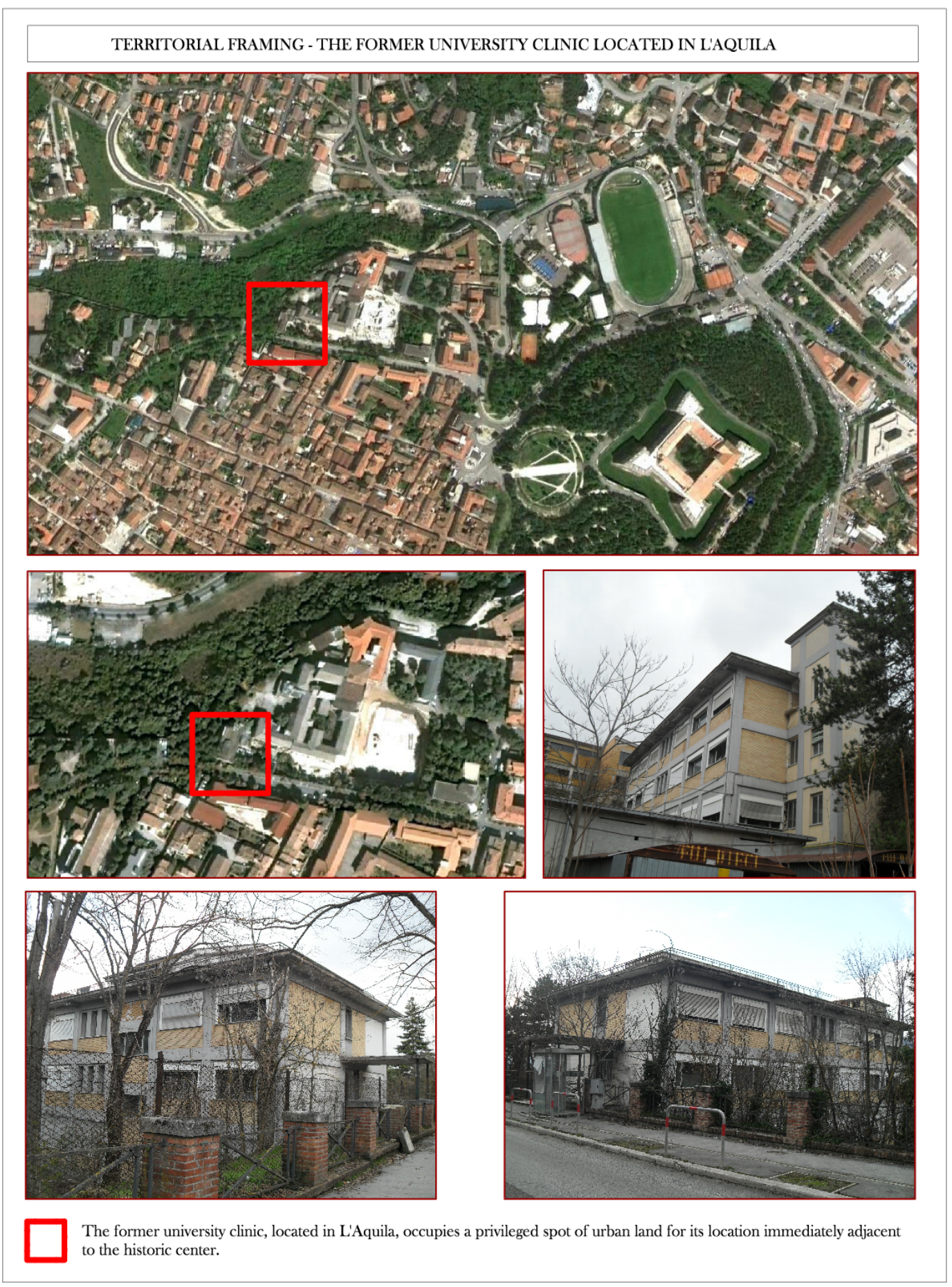

Figure 1: Territorial framing. The former university clinic, located in L'Aquila, occupies a privileged spot of urban land for its location immediately adjacent to the historic center but not so close to have a large park all around.

intervention strategies, which are standardized and perfectly repeatable, were explicated by meticulously changing the conditions to the contour. In fact, in the scientific panorama, the operational instruments that are being defined in many applications aim to provide interdisciplinary decision support. Given the complexity of the problem, they seek to define a methodology to identify the eligible intervention strategies which aim at upgrading the building in order to fulfill the new competency frameworks, new normative models, economic commitments, purpose of use and energy and environmental performance [6]. In short, the regeneration of existing assets goes through the elaboration of space-typological reconfiguration strategies and the adaptation of the plant-casing system in view of a reduction in consumption compared 
to the initial state. The L'Aquila case is a great opportunity to experiment the integration of radical seismic improvement operations with virtuous energy.

The first approach to the existing one involves a careful diagnosis by collecting as much information as possible about the artifact. In order to achieve this result an accurate emphasis on the existing is necessary that will guide step by step technological and morphological transformation. The setting that is too often present in the historic centres of our cities is that of buildings which have original deficit and are largely inadequate in a period of uncontrolled building industry. Most of them are almost completely unaware of what has to be controlled [7] and which, rarely, are in a state of total disuse that shows an advanced biological degradation due to the very few or inexistent ordinary and extraordinary maintenance. To exasperate the situation there are a lot of telluric movements that contribute to the emptying of the smaller centers and to the consequent abandonment of the collapsing buildings, thus causing the decay and the loss of quality of materials [8].

It is necessary to protect and enhance aggregates and artifacts because they are a testimony of the cultural identity and of the evolution of human settlements over time. It is important to know their constitution, their rule, their quality and the state of conservation to ensure the appropriateness of the exploratory phases with respect to the issues investigated and, finally, to guide project decisions (Figure 2).

\section{METHODS}

Taking into account cultural and ecological diversity is the central node of technological experimentations aimed at the regeneration of the existing building heritage, by disregarding the now-acclaimed tendency to homologation of constructive techniques without taking into account the context. It starts with information from a careful diagnosis of the building to define repeatable intervention models but giving the attention to the peculiarities of the single building and to the constraints imposed by the surrounding environment and by the illustrious exemplars. How the atmospheric agents act on the built is detectable through observation and analysis of degradation, however, tracking down its causes and preventing its phenomena involves a scientific approach where the building is not the only protagonist, but it is considered
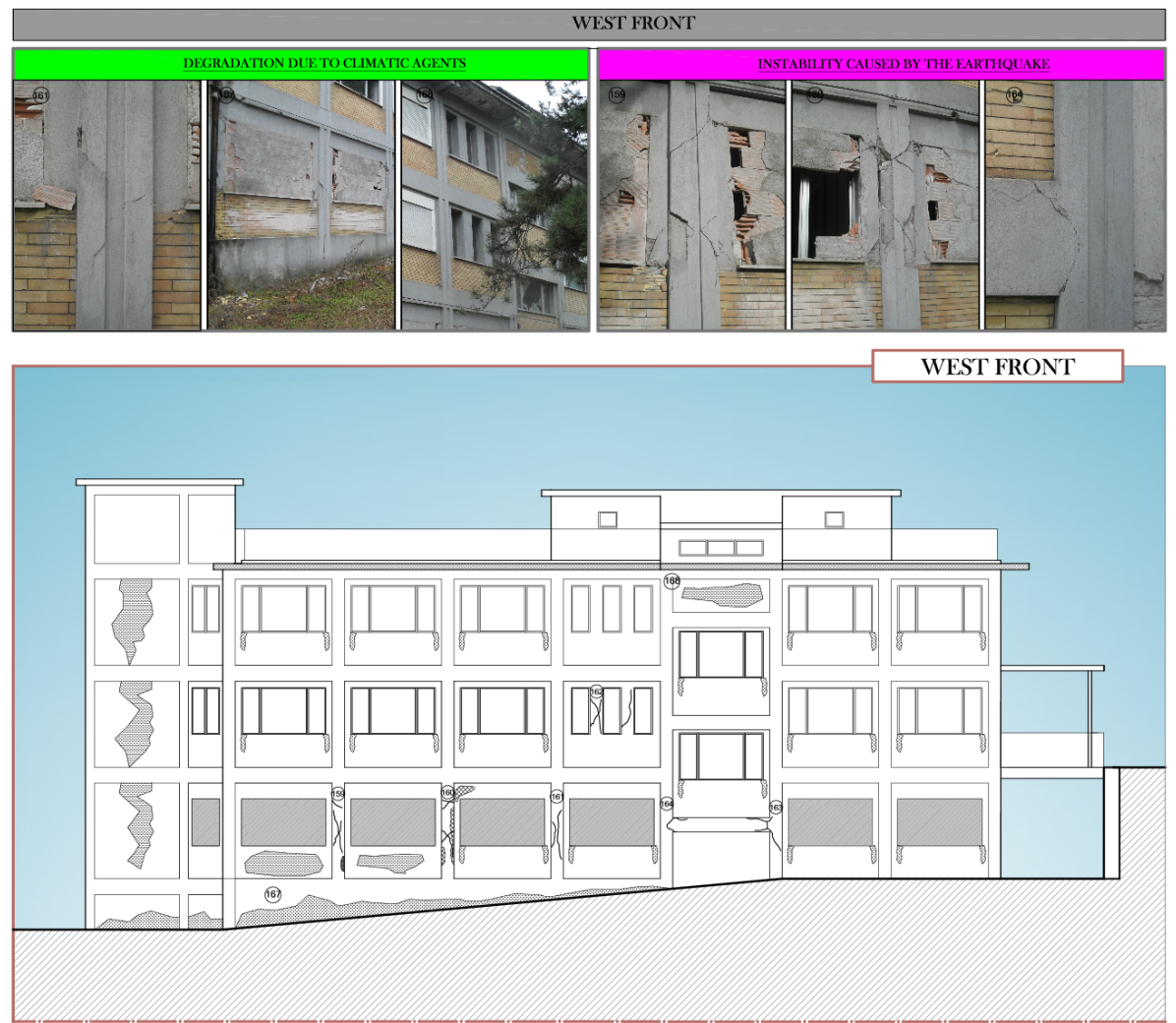

Figure 2: Analysis of degradation. The building fell into disuse before the 6th April 2009 earthquake and therefore, in addition to the damages created by the earthquake, there is the unreal maintenance to be added thus the analysis is different between the seismic and bioclimatic degradation. 
in constant exchange and balance with the context and with the environment. The depth of the climatic conditions of the site where the building is located is the starting point for a responsible and efficient design that tends to minimize energy consumption and to increase user comfort. Assessing the impacts of climate on man and its derivations, defined as the built environment, allows alignment with the ecosystem conforming to nature and exploiting positively the potential offered for free in a view of "capitalization" of the natural heritage. It is therefore important to describe the main atmospheric phenomena affecting the energy balance of the building. In this way, it becomes an ecosystemic approach to the issue, referring to the concept of 'circular economy', which is the main topic of the green economy, introduced by the recent Global Action Plan of the European Community [9]. Solar radiation is the primary source of energy on earth and determines climatic conditions everywhere and, above all, in the Italian microclimate it becomes indispensable to control the incidence of radiation both in summer and in winter, being on latitude in which seasonal variations are considerable. The orientation of the building is a very important aspect because studying the position of the shadows on the different prospects determines which portions of the building have the most unfavorable conditions in summer and winter. In winter months the faces that are shaded throughout the day, are subject to problems that can be traced not only on the construction casing, such as biological degradation and condensation problems, but that affect the inner compartments creating an unhealthy work environment, air humidity, greater energy expenditure to ensure lighting and heating, and poor natural lighting. Instead, in summer months, never shaded prospects throughout the day have some obvious problems, including the possible overheating, excessive natural lighting, unhealthy air, and energy expenditure to ensure cooling and glare phenomena. The designer should use these studies and find suitable solutions, avoiding the many problems mentioned above, always in order to guarantee optimal conditions of comfort (Figure 3 ).

Exploiting fresh summer winds could be an important aid to passive cooling by counteracting the impact of solar radiation on the exposed faces. In addition, the use of evergreen tree cover may partially overcome the impact of the cold winter winds. This technology favours various degradation phenomena on the building envelope; in this way a dialectical and reciprocal connection between the nature of the object of the design intervention and three outer macroeconomic areas, local microclimatic and domestic demanding will be established [10].

In this context of environmental development, the potential of vegetation is rediscovered and plays a fundamental role in the design. Providing natural shielding to the wind and the sun significantly improves the microclimate conditions around the buildings and limits the sunshine on the ground and the temperature range (Figure 4) in a renewed vision. After the change in the use of the soil that affected the environment as the anthropomorphic process grew, mortifying and downgrading the value, reducing it to a simple aesthetic and ornamental feature. This is observed in urban areas almost free of vegetation cover with a high rate of atmospheric pollution, an increase in precipitation in different forms, rain, snow, and hail, and these entities, though short-lived, irreversibly affect the built environment by triggering degradation and

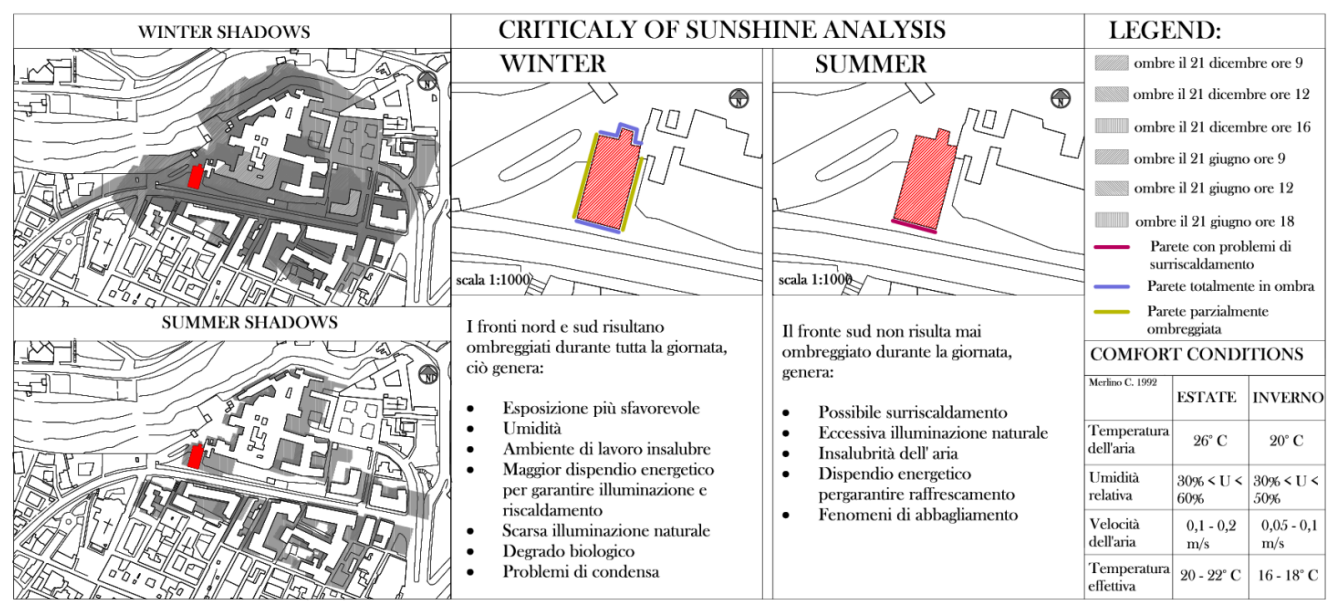

Figure 3: Sunshine Analysis. Through the study of location of the shadows on the portion of territory, we can know the portions of the building shaded in summer and winter. 


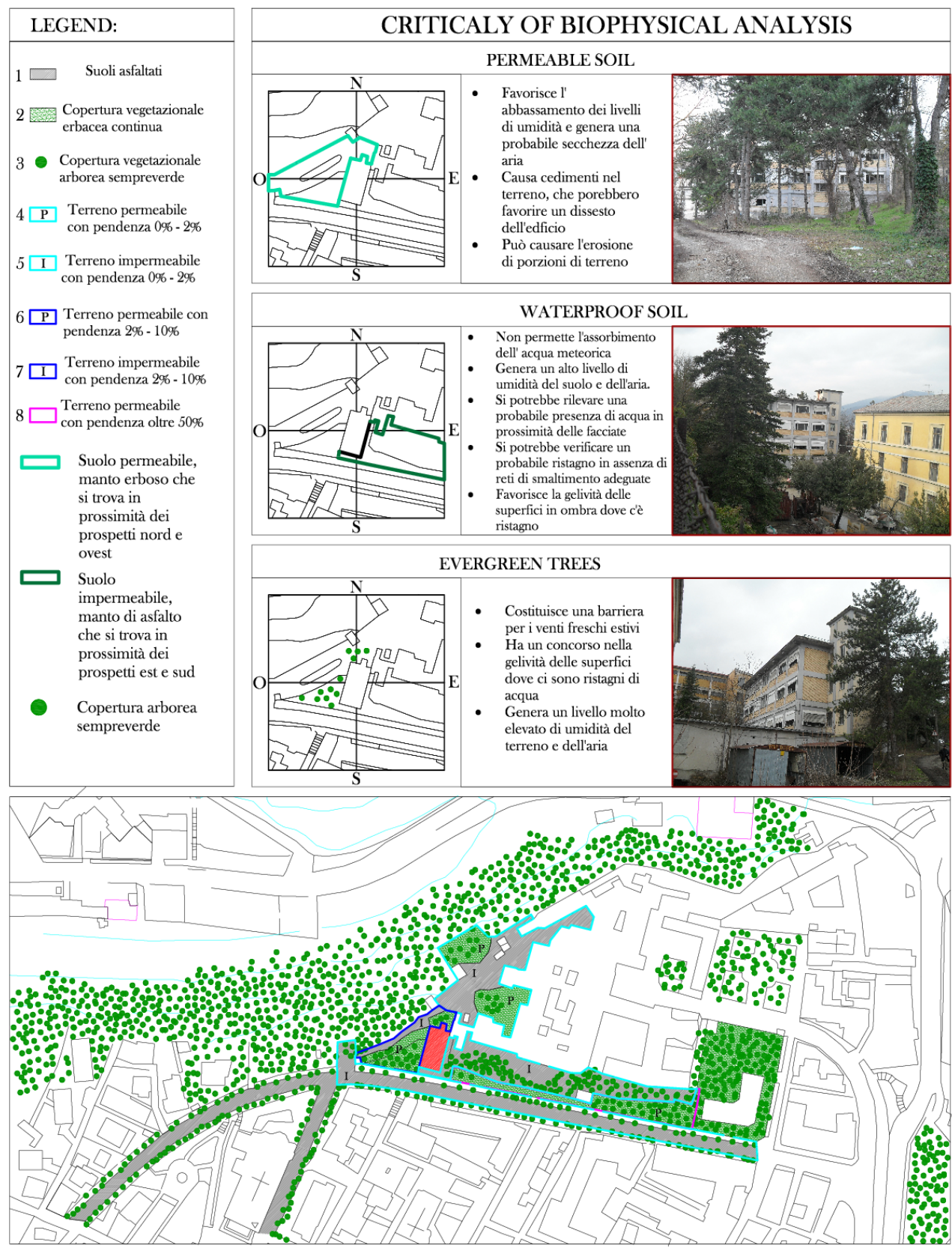

Figure 4: Soil analysis. Include the physical characteristics, the slope, and the vegetation of the soil.

encouraging efflorescence, molds and small-scale formations of vegetation.

In order to avoid the above-mentioned negative aspects, it is necessary to establish a conscious interface with the outline conditions until it will be known, controlling and directing them in the immediate part of the project, so it is essential, for exploiting the positive effects of ventilation (Figure 5), its contextualization in the project site [11]. The cold winter winds greatly affect the building envelope by cooling it, penetrating the joints, promoting biological degradation and condensation problems. In order to partially overcome these problems, evergreen trees or hedges can be provided to form a barrier to the currents. Even if, just a strongly insulated and waterproof casing is able to have a positive impact on the thermal requirement, producing a decrease in natural cooling by adversely affecting the dissipation of excess heat generated by solar radiation and human activities.

In large cities the combined effect of the sheltered zone of the crowded buildings causes a climate change with respect to the conditions in a non-urban area. This phenomenon is known as "Urban Heat Island (UHI)", despite the fact that we still cannot completely avoid 

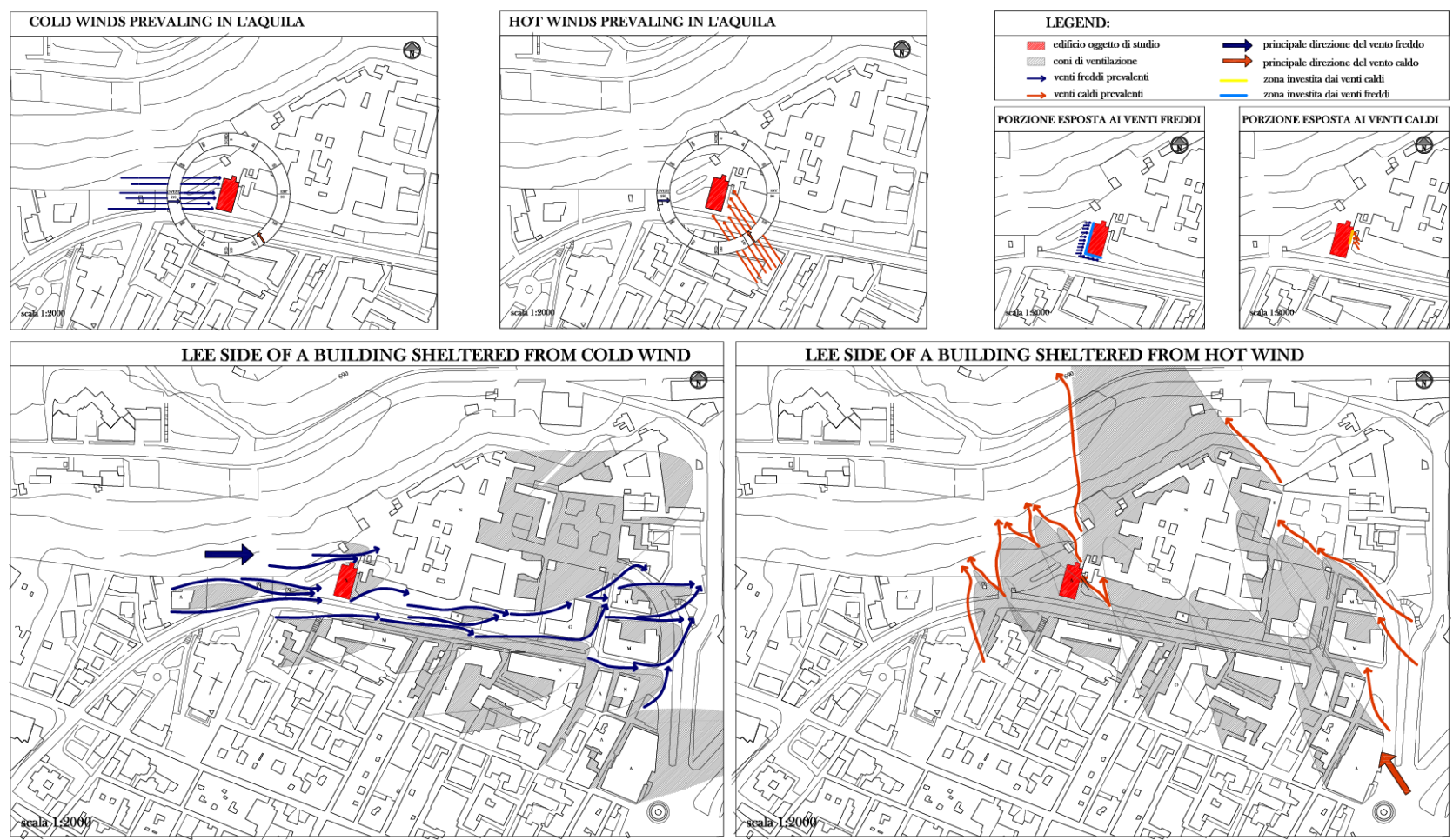

Figure 5: Ventilation analysis. About the study of the ventilation diagrams of the city of Aquila, we can conclude that the cold winds of the winter months give off from the west, and the hot summer winds come from the southeast direction.

the adverse effects in dense anthropomorphic contexts. A study of over 220 projects with monitoring and simulation campaigns suggests that we oppose the ICU using methods that utilise water systems and urban green technologies. It is also found that the mitigation potential amplifies by aggregating more techniques between them. It is therefore necessary to rethink the urban context in its entirety using innovative materials that keep the temperatures of the external sources surfaces low, making them work as heat sinks [12].

Precipitation, sunshine and ventilation are closely linked to the climatic zone considered. Building form is a proof of all this since it is a powerful element of energy performance control in buildings. As evidence of this, since ancient times, we can trace specific building forms according to various climatic contexts: compact shapes in cold climates and articulated shapes in hot-humid climates to facilitate the movement of air masses.

This explains the complexity of existing building construction interventions. Many factors need to be considered, including respect for the aesthetics of sites and the compatibility of the proposed interventions. It is no longer aimed at the mere figurative and morphological transformation of the territory but to the integration of the energy saving systems with the building, tending to a new form of architecture that integrates society and nature and that leads to an innovation of architectural-spatial language. The building is designed by abandoning the exclusive stylistic research and outlining a new architectural language. There is, therefore, a close relationship between the transformational processes of the landscape and the energy issue. We are in a moment of epochal change: from an exaggerated and without rules consumption of non-renewable sources we are shifting to the concept of employment of renewable sources as the basic concept of the construction world. The building becomes a "unicum" as it is located in a given geographical area that has its own climatic characteristics and a certain cultural heritage from which the various construction materials are emerging to an ever-higher ecological value with an ever-lower gray energy [13].

\section{Strategies}

It comes to light the importance of investigations on the envelope and its technological exploration on adaptation, borrowed theme from biology and transposed in the ability to change its characteristics through the enhancement of environmental parameters aiming to reduce energy consumption, improve insider and outer comfort and habitability [14]. 
It is universally recognized, however, that sustainable recovery goes hand in hand with social upbringing, with the aim of improving the quality of life of communities by eliminating the marginalization phenomenon that afflicts entire neighborhoods [15] and generating perfect solutions into the cultural reality. The purpose is to attract the interest of the community to the responsible use of energy resources, ensuring the necessary living comfort. In regards to the valuation of assets in a non-destructive manner, the energetic retrofit is associated to the reconfiguration of the aesthetics of the town, inserting in a synergistic way the new energy-saving technologies to the material and spatial qualities, with a careful control of the detail and, above all, of the wrap that mediates between inside and outside. It is necessary to solve the problem of thermal bridges and, the insulation of the outer boundary and walls is the better method, even if its application on the buildings could create some problems due to the irregularity of the façades. However, it is an important medium to solve problems concerned to the problems with the context, to rethink its architectural features and redefine their composition with constructive logics that tend to reduce the contrast with historically consolidated architecture. Ventilated façade insulation encloses all the benefits of the external insulation without having the disadvantages; in fact, it permits to recover the perfect planarity of the walls and to allow the circulation of air between the coating and the insulator. It exploits the natural ventilation created in the hollow space, underlining the energetic performances during cold and hot seasons. It is also necessary to consider the extreme versatility of the materials used; the outer building covering in fact, can be made up of panels of a wide variety of materials, such as photovoltaic modules. Innovation ideas often derive from the transfer of technologies from other areas that support formal architectural experimentation, as is the case with the Integrated
Photovoltaic System [16] where photovoltaic modules replace building covering materials by taking the functions and giving designers solutions that can enhance human genius, although in some cases the inclination is not optimal. The compromise to achieve is to get the best performance from the plant and a valid aesthetically solution, enhancing the formal appearance of the product in view of its reintegration into the urban context.

As part of the research of the building envelope aimed at the realization of the intelligent building, the photovoltaic systems integrated in the horizontal and vertical facades have already been extensively developed in scientific literature and design practice, yet an innovative derivation is its use for outdoor flooring and in an experimental installation, there is a reduction in surface and ambient temperature compared to traditional flooring [17]. thanks to the integration with the electronic we can synchronize artificial conditioning and atmospheric factors, ensuring a complementary innovation of materials, technologies and electronic components in an holistic view of the building-plant aimed at achieving the new frontier of energy saving: the positive energy (Figure 6).

Efficiency, understood as the optimization of the governance of the various elements of production and consumption put into the system, means: security of energy supply, understood as system protection from accidental and deliberate events that could alter its functionality and reliability, understood as the ability to ensure the stability of energy supply and certification of emerging data.

In this context, the building is no longer just a consumer subject but also becomes a producer of energy, creating the concept of "prosumer"; the artifact is both producer and consumer.

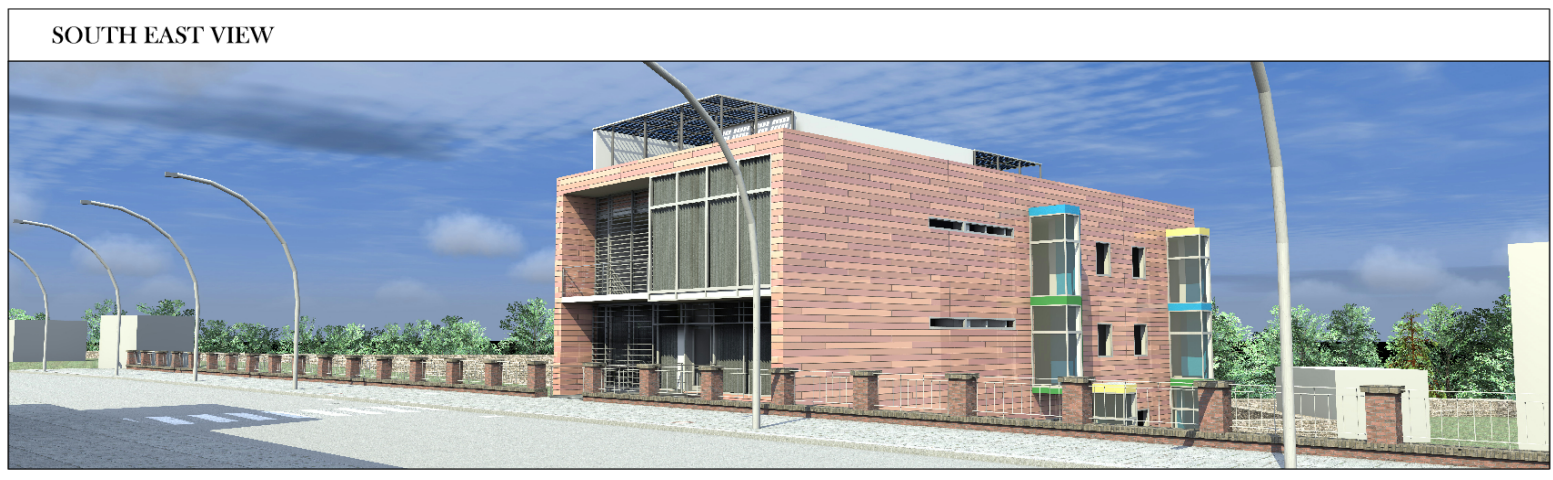

Figure 6: Images. The transformations and additions on the building envelope. 
The energy improvement of an existing building comes from many factors of sustainability control, including the integration of active and passive capturing solar systems. The first ones impose economic evaluations about the time to get the investment back from the costs and the incomes of the intervention and exercise. The second ones take the free energy supply of the sun and the possible natural resources of the local microclimate without the use of mechanical means fueled by exogenous sources of energy distribution, but both sources imply a discontinuity and are subordinated to a component of intrinsic unpredictability. Only through the very careful management of energy starting from the project, it is easier to get far from the simplicity of the engineering plant, and in this sense, scientific research is geared towards adapting production to the requirements and the storage of the generated energy making the architectural and technological-environmental characteristics of the architecture [18].

The intervention of adding is linked to the logic of a requalification process that wants the implementation of the energy performance of a construction product that is no longer able to satisfy the needs of contemporary living through the change of form that has always been linked to the users need to control and manage internal comfort conditions [19]. It is beyond doubt that the theoretical foundation of parasitic architecture is ancient, and it can be found in functional dynamics, such as the adding of small volumes for adding a bath in the house. For this reason, we can refer to illegal building and an example of this, are solar greenhouses (Figure 7). Despite the negative perception inherited by the law, the green house establish a favored space because, thanks to flexibility of the closing system and the use of solar shading systems, it guarantees the use of it during the winter and the summer redefining the thermal behavior of the structure but also the functional one because it re-plans the internal distribution.

\section{CONCLUSIONS}

The perfect and harmonious mix of environment and building, through the valorization of natural passive bioclimatic components, it favors the production of "clean energy" on site and thus allows the building to be released from the global logic of centralized production by promoting a self-produced energy network that aims to reduce energy consumption and reduce harmful emissions. The purpose is an integrated model of production and self-production of energy that leads to the sharing, regulation and creation of a territorial network of which the single citizen is the protagonist. The activity is still taking the first step, but innovation trends can be explored through studies of the typology, age, technological systems and building envelopes studied in the particular urban compartment and by analyzing the comparison between energy demand and supply. It tracks the actual energy demand, the results, associated with the available resources must be optimized by adapting existing energy infrastructures. In fact, the traditional distribution of energy, with a seamless extension, is leaving the place to the use of smart grids as networking systems that intelligently integrate all connected users, both manufacturers and

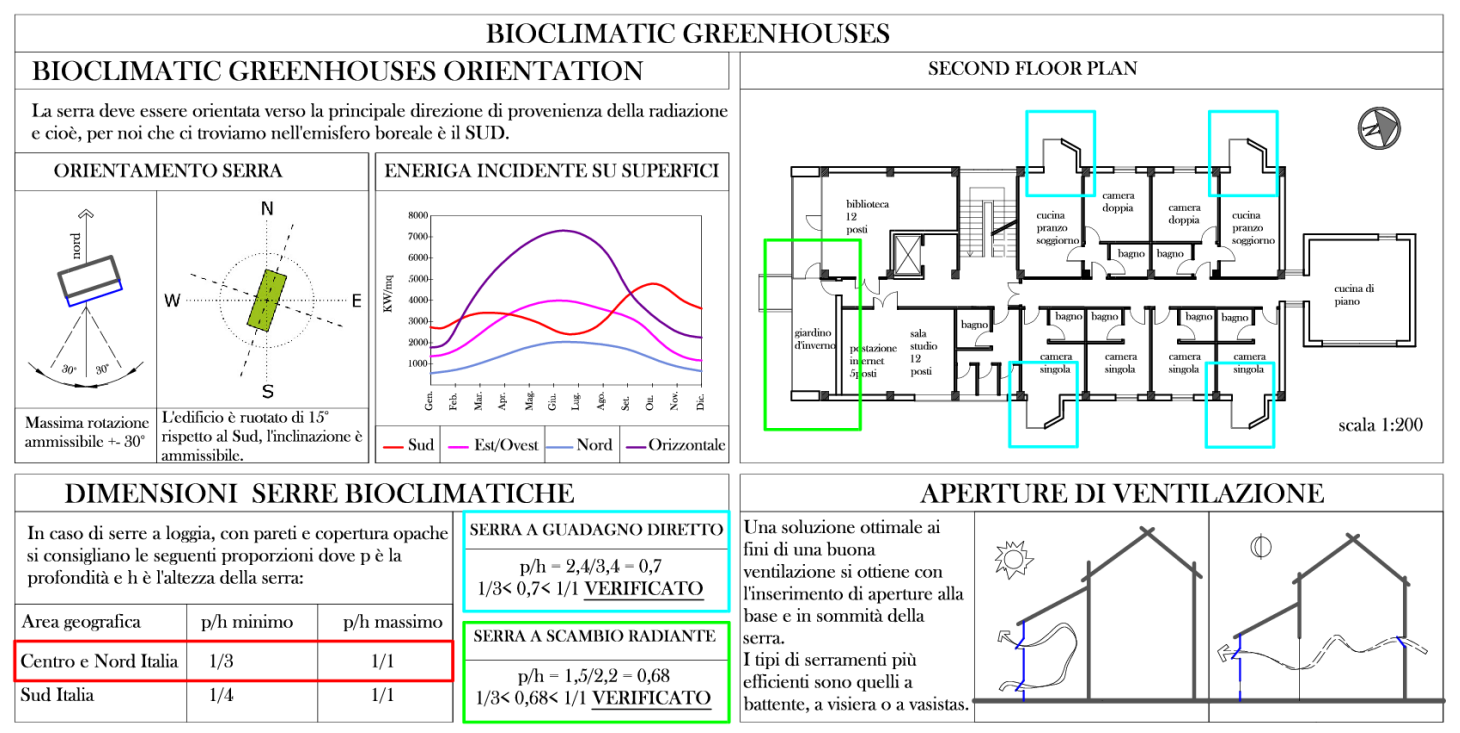

Figure 7: The additions. Insertion of bioclimatic greenhouses in relation to the pre-existing structure. 


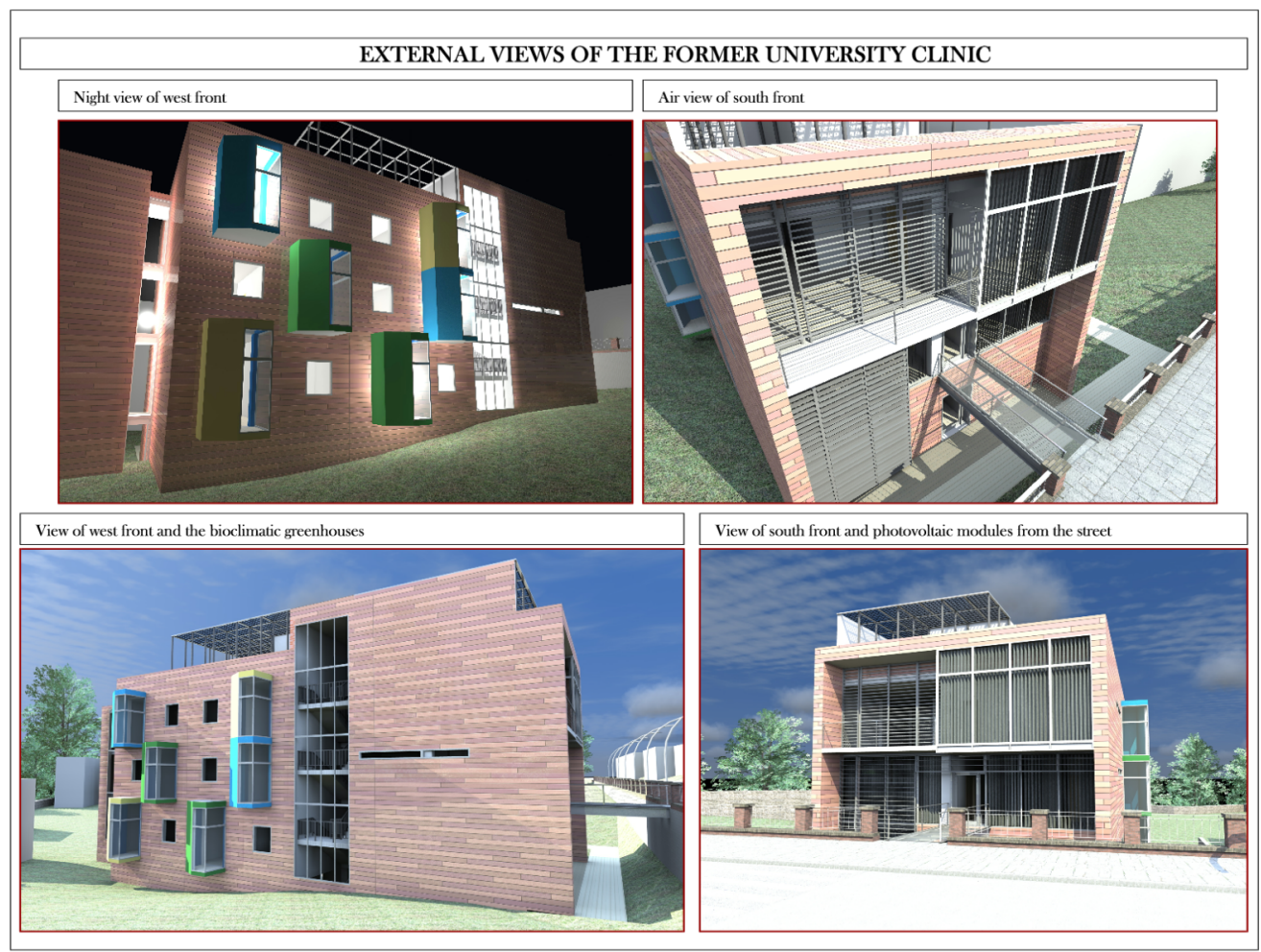

Figure 8: Images. The transformations and additions. The new former university clinic of L'Aquila.

consumers, in order to efficiently distribute energy (Figure 8). In any case, the quality of the project and the climatic characteristics of the site remain the basic prerequisites for a regeneration intervention that can be considered sustainable and which guarantees the durability of the building and its adaptability to the context [20].

\section{NOTE}

Elisa leie is assistant tutor in courses of Architectural Technology at "G. d'Annunzio" University of Chieti-Pescara, Department of Architecture. She is member of cluster "Nearly Zero Energy Building" (SITdA - Italian Society of Technology of Architecture). This contribution synthesyses the experimental project and metholodological approach developed with prof. at L'Aquila University.

\section{REFERENCES}

[1] Angelucci F, Introduzione. La costruzione del paesaggio energetico. In Angelucci $F$, editor. La costruzione del paesaggio energetico. Milano: FrancoAngeli 2011.

[2] Ardente, et al. Energy and environmental benefits in public buildings as a result of retrofit actions, in Renewable and Sustainable Energy Reviews 2011; 15(1): 460-470.

[3] Lucarelli MT, Mussinelli E, Trombetta C. Sistemi Cluster in progress la tecnologia per l'architettura in rete per l'innovazione. Maggioli 2016.
[4] Tucci F. Involucro, Clima, Energia. Qualità bioclimatica ed efficienza energetica in architettura nel progetto tecnologico ambientale della pelle degli edifici Envelope, Climate, Energy. Bioclimatic quality and energy efficiency in architecture in the environmental technological design of building skins, Altralinea, Firenze 2014.

[5] Lewis O, Sadhbh N, Borghi A. Building energy efficiency in European cities, Urbact 2013.

[6] Battisti A, Tucci F. Qualità ambientale ed efficienza ecologica, energetica e bioclimatica in architettura, in Techne. Journal of Technology for Architecture and Environment 2013; 6: 158-159.

[7] Battisti A, Tucci F. Qualità ambientale ed efficienza ecologica, energetica e bioclimatica in architettura, in Techne. Journal of Technology for Architecture and Environment 2013; 6: 166-167.

[8] Marmori A. Puccini L. Scandellari V. Van Riel S., Architettura e città, problemi di conservazione e valorizzazione. Altralinea 2015.

[9] EC (European Commission), Report on the Implementation of the Circular Economy Action Plan, Brussels [COM(2017)33]. 2017.

[10] Pallasmaa J. The Thinking Hand. Existential and Embodied Wisdom in Architecture. John Wiley \& Sons London 2010.

[11] Brophy V, Lews O. A green Vitruvius. Earthscan 2011.

[12] Santamouris M, Kolokotsa D. Urban Climate Mitigation Techniques. Taylor \& Francis 2016.

[13] Petzet M, Heilmeyer F, Reduce Reuse Recycle, Architecture as Resource, Hatje Cantz Verlag, Berlin 2012.

[14] López M, Rubio R, Martín S, Ben C. How plants inspire façades. From plants to architecture: Biomimetic principles for the development of adaptive architectural envelopes. Renewable and Sustainable Energy Reviews 2017; 67: 692703.

https://doi.org/10.1016/j.rser.2016.09.018 
[15] Valitutti A. Tecnologie di riconversione dell'ambiente costruito. Alinea 2009.

[16] Vincenti A. Sistemi fotovoltaici per l'autoconsumo. lesl 2015.

[17] Efthymiou C, Santamouris M, Kolokotsa D, Koras A. Development and testing of photovoltaic pavement for heat island mitigation. Solar Energy 2016; 130: 148-160. https://doi.org/10.1016/j.solener.2016.01.054

[18] Loonen RCGM, Trčka M, Cóstola D, Hensen. Climate adaptive building shells: State of the art and future challenges. Renewable and Sustainable Energy Reviews 2013; 25: 483-493.

https://doi.org/10.1016/j.rser.2013.04.016
[19] Fiorito F, Sauchelli M, Arroyo D, Pesenti M, Imperadori M, Masera G, Ranzi G. Shape morphing solar shadings: A review. Renewable and Sustainable Energy Reviews 2016; 55: 863-884.

https://doi.org/10.1016/j.rser.2015.10.086

[20] Hausladen G, Tucci F. Cultura tecnologica, ambiente, energia: prospettive della ricerca e della sperimentazione, in Techne. Journal of Technology for Architecture and Environment 2017; 13: 63-71.

Received on 18-11-2017

Accepted on 01-01-2018

Published on 28-02-2018

DOI: https://doi.org/10.6000/1929-6002.2017.06.04.3

() 2017 Elisa leie; Licensee Lifescience Global.

This is an open access article licensed under the terms of the Creative Commons Attribution Non-Commercial License (http://creativecommons.org/licenses/by-nc/3.0/) which permits unrestricted, non-commercial use, distribution and reproduction in any medium, provided the work is properly cited. 